\title{
Utilization of solar energy for sea water and brackish water desalination using vacuum pressure and number of trays variations
}

\author{
Riana Ayu Kusumadewi ${ }^{1}$, Suprihanto Notodarmodjo ${ }^{1}$, and Qomarudin Helmy ${ }^{1}$ \\ ${ }^{1}$ Universitas Trisakti, Environmental Engineering Department, Faculty of Architecture Landscape and Environmental Technology, \\ Jakarta, Indonesia
}

\begin{abstract}
Surface water pollution caused by industrial, agricultural, and domestic waste limit the availability of clean water sources. One solution is to use sea water as a source of clean water. Seawater desalination using solar energy is now growing. The purpose of this research is to study the effectiveness of desalination equipment with variation of vacuum pressure, number of trays, and type of feed water. First, the environmental conditions were measured, i.e. the intensity of solar radiation, ambient air temperature, and relative humidity. Then the distillator efficiency by variation of vacuum pressure, number of trays, and type of feed water was measured. From the result of observation, it was found that with radiation intensity ranged from $3967.86-6459.99 \mathrm{~W} / \mathrm{m} 2$.day, ambient air temperature $22-28^{\circ} \mathrm{C}$, and relative humidity $55-$ $80 \%$, distilled water produced was $7595-11,146 \mathrm{ml} /$ day. The distillator efficiency for pressure of -0.05 ; $0.1 ;-0.15,-0.2 ;-0.25 ;-0.3$ bar respectively were $25.54 ; 29.45 ; 29.56 ; 30.18 ; 30.90$; and $37.77 \%$. Distillator efficiency for evaporator from without tray until five trays were $24.89 ; 29.01 ; 27.88 ; 30.03 ; 34.05$; and $37.77 \%$. It was found that optimum distillator efficiency achieved at vacuum pressure of -0.3 bar and five trays in evaporator. Distillator efficiency for sea water (efficiency of $21.79 \%$ ) was lower than brackish water (efficiency of $37.77 \%$ ).
\end{abstract}

\section{Introduction}

The rate of water consumption in the world has doubled every 20 years, more than twice the rate of human growth. Some parties calculated that by 2025 , water demand will exceed supply until it reaches $56 \%$ [1]. On the other hand, contamination of surface water (rivers and lakes) caused by industrial, agricultural and domestic wastes in large quantities can limit the availability of fresh water sources [2].

Water resource that is not limited in quantity is sea water, but its quality is very bad due to it contains very high salinity or TDS (Total Dissolved Solid) [3]. To overcome this problem, one way is by applying sea water treatment technology. The processing of sea water into fresh water is known as desalination process [4].

Desalination is a separation process used to reduce the dissolved salt content of saline water to a certain level so that water can be used [5]. Desalination process involves three liquid streams, which are feed in the form of salt water (such as sea water), low salinity products, and high salinity concentrate [6].

The whole process of desalination obviously requires energy to remove the salt from seawater. If desalination is conducted with conventional technology, it would require the fossil fuels in large quantity (fresh water production of $1000 \mathrm{~m}^{3} /$ day requires 10,000 tons of oil per year), while the availability of the fuel decreases, it is necessary to use other energy source, one of them is sea water purification with solar energy [7]. Solar energy is a renewable energy, safe, free, and free of pollution (no $\mathrm{CO}_{2}$ emissions). Solar energy is a promising solution to save costs. Furthermore, Indonesia is a country that has an abundance of solar intensity, which is average 4.8 $\mathrm{kWh} / \mathrm{m}^{2}$.day.

For large water production, conventional desalination technologies such as multi stage flash (MSF), multiple effect boiling (MEB), reverse osmosis (RO), vapor compression (VC), and others have proven to be technically and economically. However, for (i) small communities where water supply is limited (up to 10 $\mathrm{m}^{3} /$ day), (ii) an area that is far from sources of water and energy (fuel), and (iii) community with low technical capacity, solar desalination is more suitable to be applied [2].

This research aims to observe effectiveness of solar desalination system under vacuum condition with a variety of vacuum pressure, the number of trays in the evaporator, and type of feed water, both quantity and quality and heat transfer occurred in the system. The practical general rule for a simple solar still is that the sunlight collection area about $1 \mathrm{~m}^{2}$ is needed to produce $3-5$ liters of water per day. Thus, the high sunlight collection area is needed with high capital costs [2]. Therefore, in this research, the place of heating,

* Corresponding author: author@e-mail.org 
evaporation, and condensation are made separately to improve the efficiency of conventional solar still.

\section{Methodology}

This saline water desalination research was conducted at PAU Bulding 7th floor (outdoor), Institut Teknologi Bandung (ITB). Observation began at 08.00 am and ended at $16.00 \mathrm{pm}$ for six weeks throughout the month of May to August 2013. This research was conducted through several steps, starting from initial characteristic of water sample. At the beginning of the observation, feed water in the form of artificial saline water was used ( $\pm 12 \%$ salinity). Input water with concentration of $12 \%$ represents brackish water in nature.

Saline water desalination process in this research can be seen in Fig. 1. Water input at first was stored in water tank, then flowed through the hose to solar collector tank. Solar energy would be absorbed by solar collector to heat water, but some of this energy was lost to environment. After water temperature reached a certain value, water was flowed into evaporator. Vacuum pump pressure in the evaporator was arranged corresponding with variation of vacuum pressure desired. Variations in vacuum pressure used were $-0.05 ;-0.1 ;-0.15 ;-0.2$; 0.25 ; and -0.3 bar. Tray variations in the evaporator from without tray until five trays was conducted. At the bottom of the evaporator would be formed water that was not vaporized (brine). Brine would be streamed back into the water tank. While the vapor would enter into condenser where in condenser, cooling water would be flowed into it so that vapor changed become liquid phase. Distilled water product would come out of the bottom of condenser and collected in a container to be analyzed its characteristic. Quantity of distilled water was measured and recorded every one hour so that it can be analyzed the efficiency of saline water desalination equipment in this research. Then after the maximum condition was obtained (seen from vacuum pressure, input water flow, and the number of trays), continued with feed water in the form of saline water with $\pm 38 \%$ o salinity, and then compared its result with feed water $\pm 12 \%$ salinity. Input water with salinity of $38 \%$ represents sea water in nature. In addition, measurement of feed water, brine, and distilled water quality parameters was conducted. Parameters tested included temperature, $\mathrm{pH}$, salinity, conductivity, turbidity, TDS (Total Dissolved Solid), chloride, ferrous $(\mathrm{Fe})$, hardness, and E.coli.

\subsection{Data analysis}

Determination of distillator efficiency is conducted by calculating the accumulative efficiency of solar desalination using this equation [8]:

Accumulative efficiency:

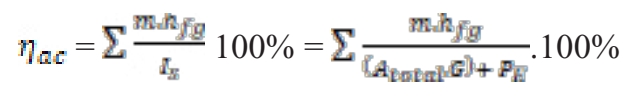

Where $m_{p}$ is distillation product mass flow rate per unit $\left(\mathrm{kg} / \mathrm{m}^{2}\right.$.hour $), \mathrm{h}_{\mathrm{fg}}$ is latent heat of vaporization $(\mathrm{J} / \mathrm{kg})$, $\mathrm{I}_{\mathrm{S}}$ is energy input in the system $\left(\mathrm{J} / \mathrm{m}^{2}\right.$.hour $), A_{\text {total }}$ is total heat transfer area $\left(\mathrm{m}^{2}\right), \mathrm{G}$ is solar irradiation $\left(\mathrm{J} / \mathrm{m}^{2}\right.$.hour $)$, and $\mathrm{P}_{\mathrm{E}}$ is electrical energy from the vaccum pump and water pump ( $\mathrm{J} /$ hour$)$.

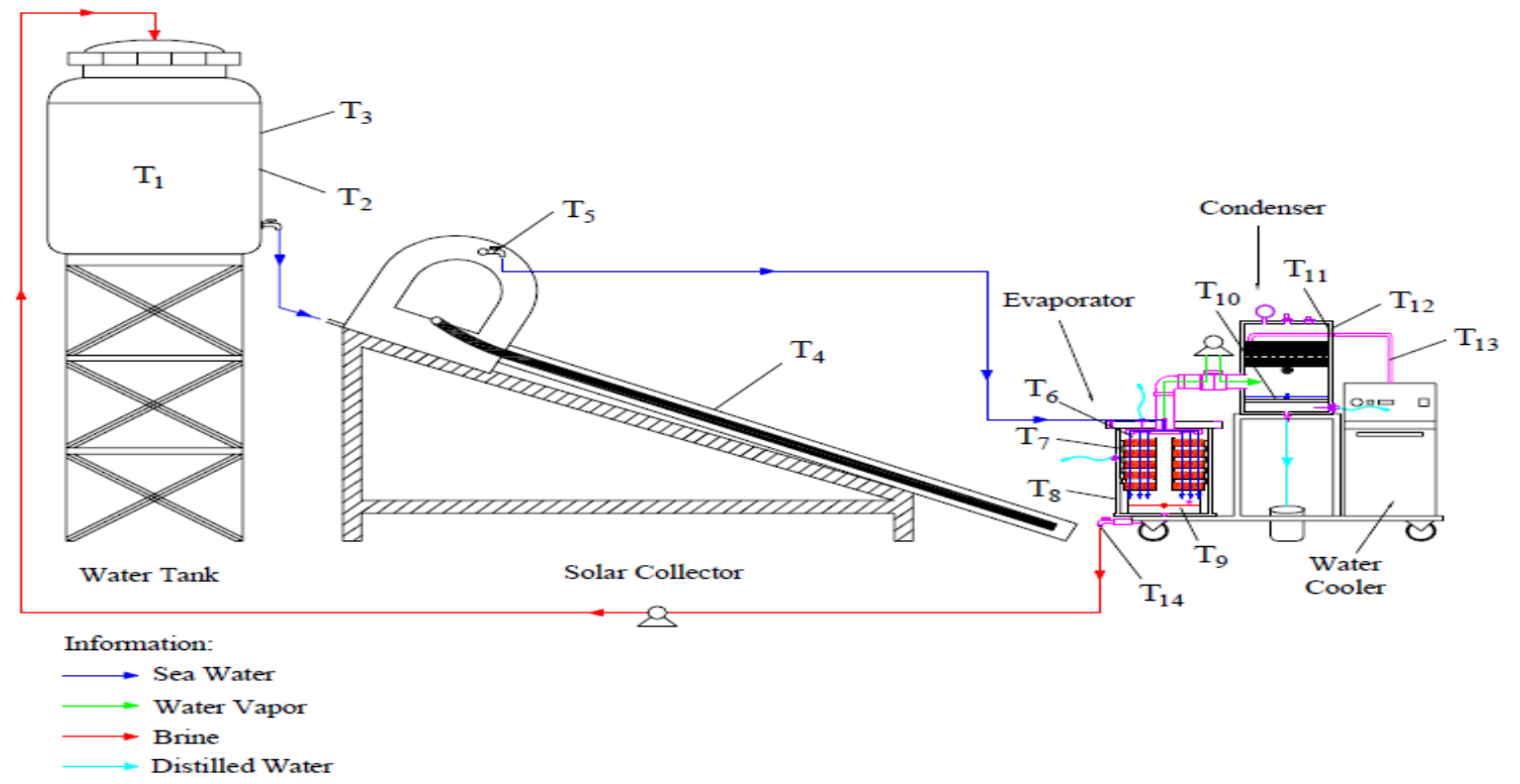

Fig. 1. Sea Water Desalination System

\section{Results and discussion}

Observation was made from 08.00 - 16.00 for the entire variations in which time- 0 showed at 08.00 , 1 st time showed at 09.00 , and so on until the 8 th time showed at 16.00. Distillator efficiency is accumulative efficiency, which is the accumulation efficiency from 08.00 until 16.00 . 


\subsection{Effect of solar radiation intensity on distilled water volume}

Solar energy plays an important role in the process of heating water in solar collector. Solar desalination techniques can be either direct or indirect [9]. The utilization of solar energy in this desalination system was done indirectly, due to solar energy is not used directly to produce distilled water, but it is only used to heat water.

The relationship between solar radiation intensity and distilled water volume can be seen in Fig. 2. The highest intensity of solar radiation occurred at 13.00 , amounting to $950 \mathrm{~W} / \mathrm{m}^{2}$ and the highest distilled water volume occurred at 14.00 , amounting to $1400 \mathrm{ml} / \mathrm{m}^{2}$.hour. The solar collector generally takes about an hour to raise the water temperature from $20^{\circ} \mathrm{C}$ to $45^{\circ} \mathrm{C}$. The solar radiation absorbed by the collector accumulates until the collector can increase the water temperature to the maximum, so that the distilled water product reaches a maximum [10].

Solar water heating systems generally consist of solar collector that collect solar energy to heat water and insulated storage tank where hot water stores [11]. The heated water is then sent to the hot water storage tank. Hot water is then recirculated through an absorbent panel and this way water temperature will increase.

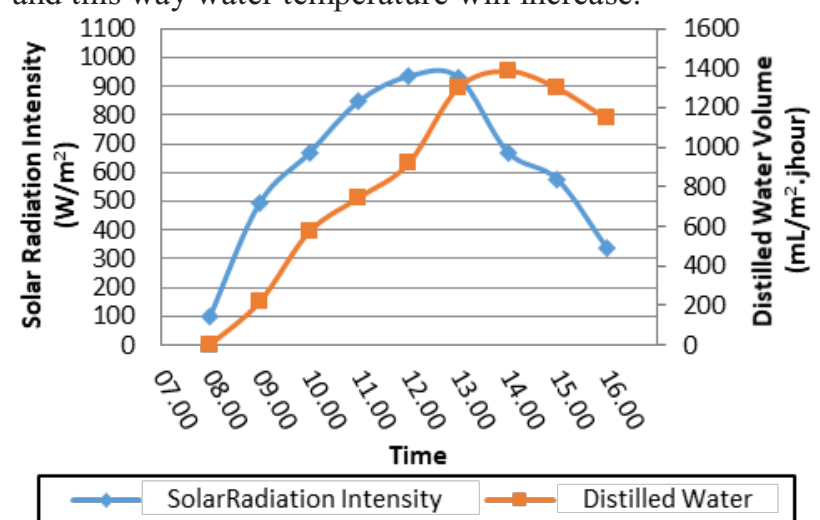

Fig. 2. The Relationship between Solar Radiation Intensity and Distilled Water Volume.

Storage techniques should be simple and inexpensive in order to keep the system costs as low as possible [9]. Effect of solar radiation intensity on distilled water volume can be seen in Fig. 3. The intensity of solar radiation is directly proportional to the product of distilled water. For a typical solar desalination unit, the amount of portable water collected daily depends on the total amount of radiation received by the unit during the day [9].

Solar collector can absorb solar radiation to the maximum in the absence of moisture attached to the cover glass that can reduce the transparency of collector as in simple solar still process. This indicates that absorption of solar radiation by this solar collector is only influenced by transmissivity of the cover and absorptivity of the collector. Transmissivity is fraction of the amount of radiated energy transmitted per total amount of energy received by a surface [11].

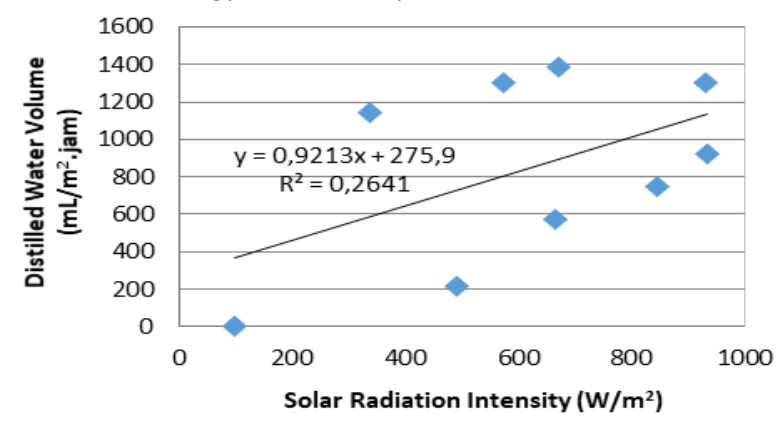

Fig. 3. Effect of Solar Radiation Intensity on Distilled Water Volume.

\subsection{Effect of air temperature on distilled water volume}

The increase and decrease in input water temperature of the evaporator is influenced by ambient temperature in the environment. Ambient air temperature will affect the absorption of solar radiation by the solar collector so that it will indirectly affect water temperature inside the collector. This water temperature of course will affect distilled water volume.

Ambient air temperature is a non specific expression used to describe the outside temperature [12]. The relationship between air temperature and distilled water volume can be seen in Fig. 4. The highest ambient air temperature occurred at 14.00 , amounting to $19^{\circ} \mathrm{C}$ and the highest distilled water volume occurred at 14.00, amounting to $1400 \mathrm{ml} / \mathrm{m}^{2}$.hour.

The distilled water product follows the ambient air temperature pattern. Increased ambient air temperature significantly affects the volume of distilled water. Ambient air temperature will increase from morning until noon and then drop back in the afternoon. This indicates that increase and decrease of ambient air temperature correlates with increasing and decreasing intensity of solar radiation.

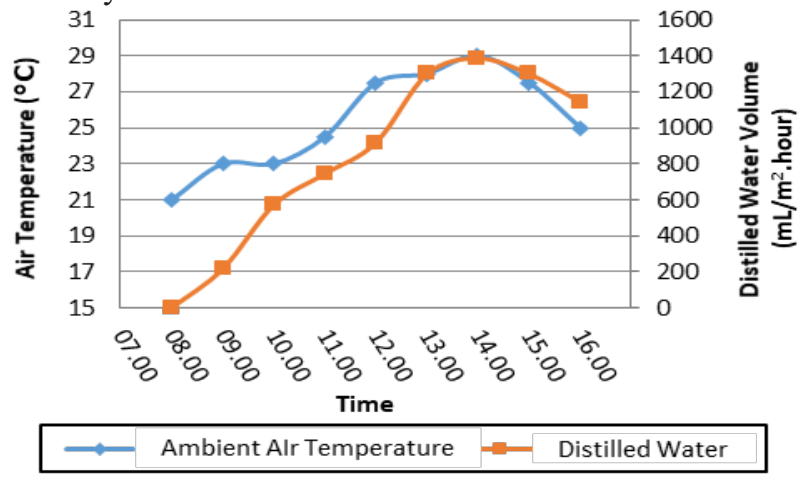

Fig. 4. The Relationship between Ambient Air Temperature and Distilled Water Volume.

Effect of ambient air temperature on distilled water volume can be seen in Fig. 5. The ambient air temperature is directly proportional to the distilled water product. Air has a type of heat that is lower than the water heat type so it requires less energy per gram to 
increase the temperature than water. Furthermore, with increasing ambient air temperature, environmental temperature will be high. Heat energy is a form of energy that moves from high temperature to low temperature [10].

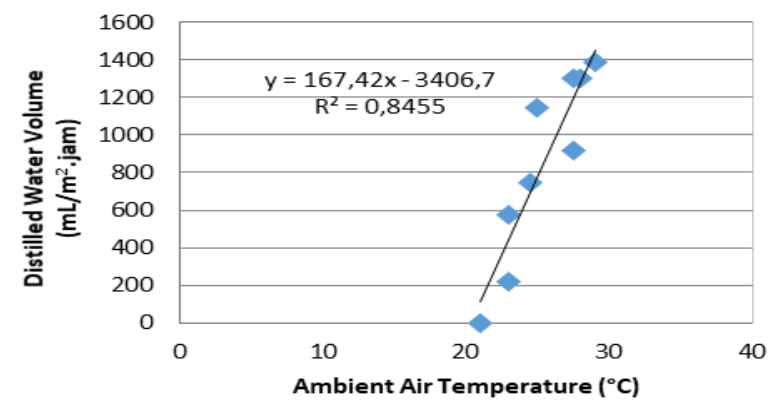

Fig. 5. Effect of Ambient Air Temperature on Distilled Water Volume.

\subsection{Effect of relative humidity on distilled water volume}

Relative humidity is the ratio of water vapor partial pressure $\left(p_{v}\right)$ to the water vapor partial pressure in saturated air $\left(p_{s}\right)$ at the same temperature [3]. Relative humidity in the environment affects intensity of solar radiation to be received by solar collector and heat transfer in desalination system. Relationship between relative humidity and distilled water volume can be seen in Fig. 6.

Fig. 6. shows that the highest relative humidity occurred at 16.00 of $70 \%$ and the lowest occurred at 8.00 of $40 \%$, while distilled water volume mostly occurred at 14.00 of $1400 \mathrm{ml} / \mathrm{m}^{2}$.hour. From Fig. 6. it can be concluded in general that the lowest relative humidity will occur during the day when solar radiation instensity is maximum, while in the morning at sunrise, relative humidity is still high. When relative humidity in the environment is high, distilled water volume is still low, then distilled water volume will increase as solar radiation increases while relative humidity decreases. Effect of relative humidity on distilled water volume can be seen in Fig. 7 .

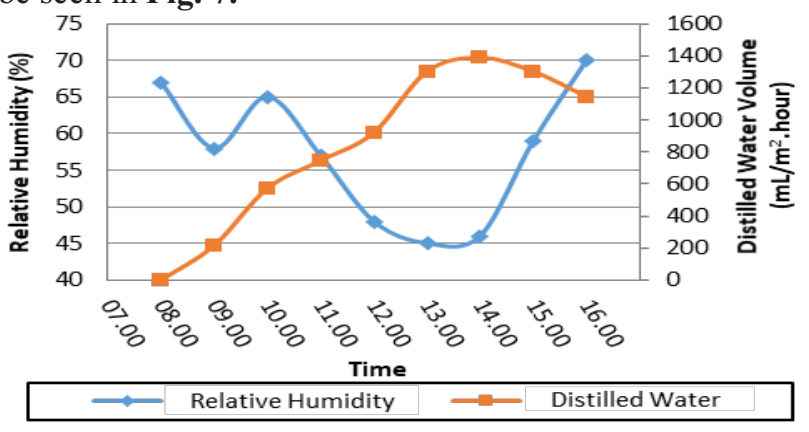

Fig. 6. The Relationship between Relative Humidity and Distilled Water Volume.

Fig. 7. shows that relative humidity is inversely proportional to distilled water volume. The greater relative humidity, distilled water volume will be lower. Air humidity indicates the amount of moisture present in the air [3]. Water vapor has a larger type of heat than air type heat so it requires more energy per gram for a certain temperature increase compared to air, meaning that water vapor is harder to heat than dry air.

In the case of water, relative humidity, where the percent of vapor pressure in the air above the liquid compared with the vapor pressure at a certain temperature reduces the velocity of evaporation. The rate of water evaporation is estimated as a straight line from the maximum point at $0 \%$ relative humidity up to a point $100 \%$ relative humidity. The lower the moisture, the more molecules evaporate [12].

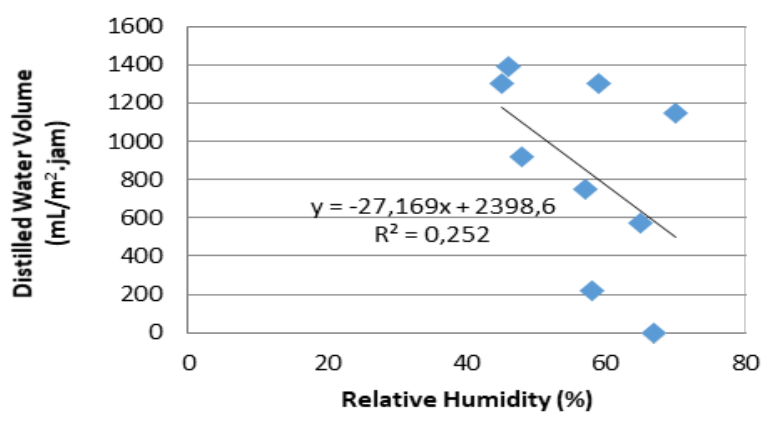

Fig. 7. Effect of Relative Humidity on Distilled Water Volume.

\subsection{Effect of vacuum pressure in the evaporator on distillator efficiency}

Evaporation rate can be improved significantly by applying external energy source in water molecules, but also by reducing system pressure [13]. In a vacuum condition, water can be evaporated at a low temperature level, thereby requiring smaller heat energy [14]. Effect of vacuum pressure on distillator efficiency can be seen in Fig. 8.

Accumulative efficiency for vacuum pressure -0.05 ; $0.1 ;-0,15 ;-0,2 ;-0,25$; and $-0,3$ bar were $25.54 ; 29.45$; $29.56 ; 30.18 ; 30.90$; and $37.77 \%$ respectively. From Fig. 8. it can also be seen that the higher vacuum pressure (the lower the air pressure in the chamber), the higher distillator efficiency. Highest efficiency was achieved at vacuum pressure of $-0,3$ bar, which was $37.77 \%$. From Fig. 8. it can be seen that the higher the vacuum pressure, the greater the efficiency of desalinator, meaning distilled water volume per total of energy produced is greater. This is due to liquid being able to evaporate either by increasing temperature or lowering pressure. Evaporation is a phenomenon in which molecules collect enough energy to break away from liquid phase and enter space above gas-liquid interface. The rate of evaporation can be increased significantly by applying an external energy source to water molecules, but also by reducing system pressure [13].

Water temperature entering into the evaporator was less than the boiling point of water at atmospheric pressure $\left(<100^{\circ} \mathrm{C}\right)$ so that it required vacuum condition so water can evaporate faster. At high temperature, some water molecules gain enough kinetic energy to reach the speed that makes water molecules escape from liquid to the space above gas-liquid surface, before they fall into liquid. When the external pressure is less than one 
atmosphere, boiling point of liquid is lower than normal boiling point [15].

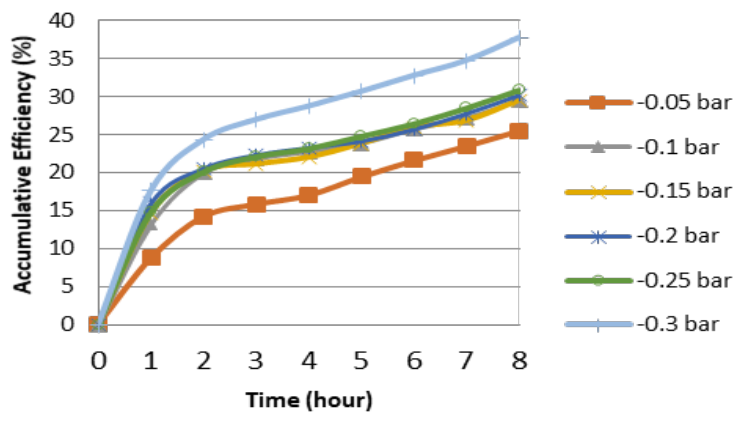

Fig. 8. Effect of Vacuum Pressure on Distillator Efficiency.

\subsection{Effect of the number of trays in the evaporator on distillator efficiency}

In this research, variation of number of trays in the evaporator from without tray until five trays was conducted. Effect of trays on distillator efficiency can be seen in Fig. 9.

Accumulative efficiency for evaporator without tray, one tray, two trays, three trays, four trays, and five trays were $20.29 ; 21.83 ; 22.25 ; 27.17 ; 24.16$; and $37.77 \%$. From Fig. 9. it can be seen that the more the number of trays in the evaporator, the higher distilator efficiency, which means more water evaporates.

Amount of heat transferred in a substance can be expressed in the equation: $\mathrm{q}=\mathrm{U} . \mathrm{A} . \Delta \mathrm{T}$ where $\mathrm{q}$ is heat transferred (Watt), $\mathrm{U}$ is overall heat transfer coefficient $\left(\mathrm{W} / \mathrm{m}^{2} . \mathrm{K}\right), \quad \mathrm{A}$ is heat transfer area $\left(\mathrm{m}^{2}\right)$, and $\Delta \mathrm{T}$ is temperature difference (Geankoplis, 2003). Based on these equation, it can be seen that the greater the heat transfer surface area, the greater the heat transferred. By adding the number of trays in the evaporator means adding heat transfer area, so that the rate of evaporation in the evaporator will increase. Evaporation is a surface phenomenon, meaning evaporation occurs on the surface of a substance rather than on the inside. Liquid molecules break away only on the exposed surface of the air [12].

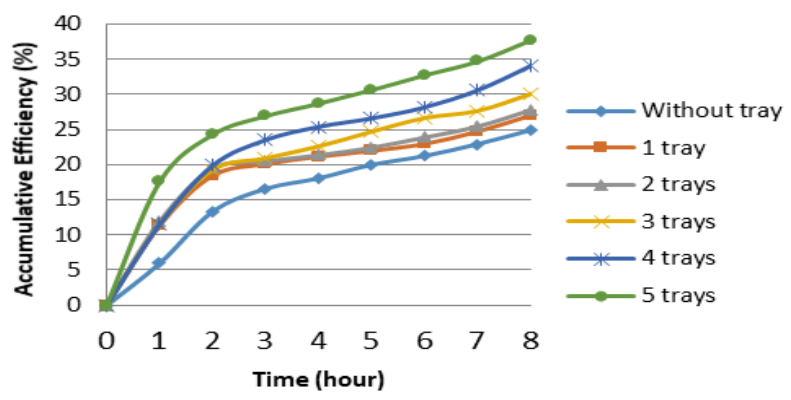

Fig. 9. Effect of The Number of Trays in The Evaporator on Distillator Efficiency.

\subsection{Feed water analysis}

In this research, feed water in the form of artificial saline water with salinity of $12 \%$ ( $10970 \mathrm{mg} / \mathrm{L}$ TDS) was used and followed by $38 \%$ feed water $(28500 \mathrm{mg} / \mathrm{L}$ TDS) after the maximum condition was reached. Distillator efficiency for each type of feed water can be seen in Fig. 10.

The use of artificial brackish water provided accumulative efficiency of $37.77 \%$ while artificial sea water provided accumulative efficiency of $21.79 \%$. From Fig. 10. it can be seen that distilator efficiency for artificial sea water (salinity of 38\%o) was lower than artificial brackish water (salinity of $12 \%$ ). Artificial sea water has higher density and molarity compared to artificial brackish water because it contains higher salt level (salinity). Density and molarity determine the decreasing of vapor pressure. When density and molarity increase, water activity and vapor pressure decrease due to different salt content, thus they reduce the rate of evaporation [14].

Sea water vapor pressure is about $1.84 \%$ lower than freshwater over the temperature range from $0-100^{\circ} \mathrm{C}$ [11]. Liquid with high boiling point tends to evaporate more slowly than liquid with lower boiling temperature. If the fluid is composed of large charge molecules, the molecules will break away at a slower rate due to more energy is needed to lift the mass and overcome the electromagnetic interaction of these molecules with each other to allow the molecules to break away [9].

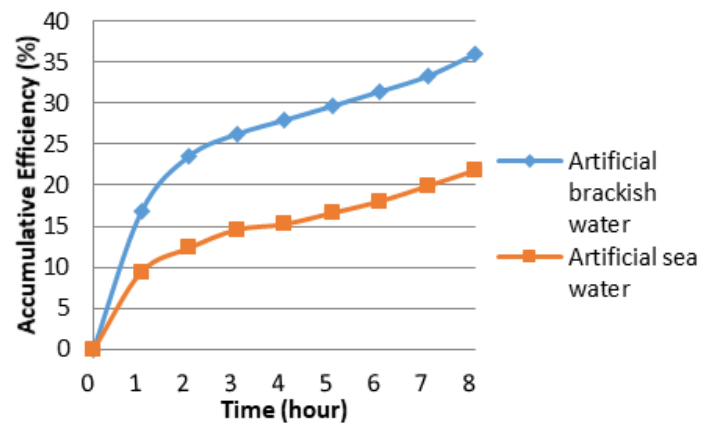

Fig. 10. Effect of Feed Water Type on Distillator Efficiency.

\subsection{Production of distilled water at various pressure}

Evaporator input water temperature is directly proportional to distilled water volume. The addition of heat energy can make it easier for molecules to escape from fluids [10]. Volume of distilled water produced under various vacuum conditions with different mean evaporator input water temperatures can be seen in Table 1. From Table 1. it can be seen that the largest distilled water volume was obtained for vacuum pressure of $-0.2 \mathrm{bar}$, ie $11,146 \mathrm{ml} / \mathrm{s}$. This was due to the highest evaporator input water temperature occurs at vacuum pressure of -0.2 bar, which was $52.9^{\circ} \mathrm{C}$.

The higher the temperature of a substance, the greater the value of the saturated vapor pressure [15]. The amount of saturated vapor pressure is correlated with the number of molecules having sufficient kinetic energy to escape from the liquid surface and enter the vapor phase. Energy (heat) is used to break the bonds that hold water molecules together so that the particles collide with each other, and the molecules become so distant that the molecules become gas. 
Table 1. Distilled Water Poduction at Various Vacuum Pressure.

\begin{tabular}{|c|c|c|c|}
\hline $\begin{array}{c}\text { Vacuum } \\
\text { Pressure } \\
\text { (minus bar) }\end{array}$ & $\begin{array}{c}\text { Cumulative } \\
\text { Solar } \\
\text { Radiation } \\
\text { Intensity } \\
\left(\mathbf{W} / \mathbf{m}^{2} \mathbf{. d a y}\right)\end{array}$ & $\begin{array}{c}\text { Average } \\
\text { Evaporator } \\
\text { Input Water } \\
\text { Temperature } \\
\left({ }^{\circ} \mathbf{C}\right)\end{array}$ & $\begin{array}{c}\text { Distilled } \\
\text { Water } \\
\text { Volume } \\
\left(\mathbf{m L} / \mathbf{m}^{2} \text {.day) }\right.\end{array}$ \\
\hline 0,05 & $5.379,5$ & 41,9 & 7.595 \\
\hline 0,1 & 5.171 & 42,9 & 8.420 \\
\hline 0,15 & $4.366,2$ & 42,1 & 8.113 \\
\hline 0,2 & $6.660,9$ & 52,9 & 11.146 \\
\hline 0,25 & 5.309 & 45,8 & 9.089 \\
\hline 0,3 & $4.925,4$ & 46,8 & 10.182 \\
\hline
\end{tabular}

\section{Conclusion}

From the result of five months of observation, it was found that with radiation intensity ranged from 3967.86 $-6459.99 \mathrm{~W} / \mathrm{m}^{2}$.day, ambient air temperature $22-28^{\circ} \mathrm{C}$, and relative humidity $55-80 \%$, distilled water produced was $7595-11,146 \mathrm{ml} /$ day. Optimum distillator efficiency achieved at vacuum pressure of minus 0.3 bar and five trays in evaporator with the highest distillator efficiency, amounting to $37.77 \%$. Distillator efficiency for sea water (efficiency of $21.79 \%$ ) was lower than brackish water (efficiency of $37.77 \%$ ).

\section{References}

1. H.Yang, Z. Sun, Z. Zhan, H. Zhang, Y. Yao. Effects of Watering Parameters in A Combined Seawater Desalination Process. Desalination 425, $77-85$ (2018)

2. H.E.S Fath, S.M. Elsherbiny, A.A. Hassan, M. Rommel, M. Wieghaus, J. Koschikowski, M. Vatansever. PV and Thermally Driven Small Scale, Stand Alone Solar Desalination Systems with Very Low Maintenance Needs. Desalination 225, 58 69 (2008)

3. G. Yuan, Z. Wang, H. Li, and X. Li. Experimental Study of A Solar Desalination System Based on Humidification - Dehumidification Process. Desalination 277, 92 - 98 (2011)

4. R. Deng, L. Xie, H. Lin, J. Liu, W. Han. Integration of Thermal Energy and Seawater Desalination. Energy 36, 4368 - 4374 (2010)

5. Reddy, K.S., Kumar, K.R., Tadhg, S., O’Donovan, and Mallick, T.K. 2011. Performance Analysis of An Evacuated Multi-Stage Solar Water Desalination System. Desalination 288 (2012) 8092.

6. Z. Chen, G. Xie, Z. Chen, H. Zheng, C. Zhuang. Field Test of A Solar Seawater Desalination Unit with Triple Effect Falling Film Regeneration in Northern China. Solar Energy 86, 31 - 39 (2012)

7. I.H. Yilmaz and M.S. Soylemez. Design and Computer Simulation on Multi - Effect Evaporation Seawater Desalination System Using Hybrid Renewable Energy Sources in Turkey. Desalination 291, 23 - 40 (2012)
8. Incropera and Dewitt. Introduction to Heat Transfer. New York: John Wiley and Sons (2002)

9. M. Al - Harahsheh, M.A. Arabi, H. Mousa, Z. Alzghoul. Solar Desalination Using Solar Still Enhanced by External Solar Collector and PCM. Applied Thermal Engineering 128, 1030 - 1040 (2018)

10. H. Aburideh, A. Deliou, B. Abbad, F. Alaoui, D. Tassalit, Z. Tigrine. An Experimental Study of A Solar Still: Application on The Water Desalination of Fouka. Procedia Engineering 33, 475 - 484 (2012)

11. K.H. Nayi and K.V. Modi. Pyramid Solar Still: A Comprehensive Review. Renewable and Sustainable Energy Reviews 81, 136 - 148 (2018)

12. A.P. Kryukov and V.Y. Levashov. About Evaporation-Condensation Coefficients on The Vapor-Liquid Interface of High Thermal Conductivity Matters. International Journal of Heat and Mass Transfer 54, 3041 - 3048 (2011)

13. L. Davoust and J. Theisen. Evaporation Rate of Drop Arrays within A Digital Microfluidic System. Sensors and Actuators B:Chemical (2013)

14. T.M. Missimer and R.G. Maliva. Environmental Issues in Seawater Reverse Osmosis Desalination: Intakes and Outfalls. Desalination 434, 198 - 215 (2018)

15. R.R. Perez, J.S. Moriano, C.G.P. Zuniga. Adaptive Expert Generalized Predictive Multivariable Control of Seawater RO Desalination Plant for a Mineral Processing Facility. IFAC PApersOnline 50-1, 10244 - 10249 (2017) 